\title{
ANNOTATED BIBLIOGRAPHY OF GENERATIVE GRAMMAR
}

\author{
Julian C. Boyd and Harold V. King \\ University of Michigan
}

A NUMBER of important books and articles on the subject of generative grammar have become readily available during the past year or two, some of them containing material that had previously been circulated among specialists but had not actually been published. It is our purpose in the following summary to give a highly selective list of those works which will help the student of linguistics to get an overall view of what has been done in this field up to the present time.

We have tried to include only those items that can easily be obtained through libraries and bookstores. Some of the items bring in examples from languages other than English, but in most cases the structure of English is the central concern. Those works that present the least difficulty to students unfamiliar with the field have been listed together in the first section. Works that are very highly technical or that are only of peripheral interest to students of linguistics have been omitted entirely.

Suggestions on other items that ought to be included, corrections on the accuracy of the entries, and comments on the appropriateness of the annotations will be welcome. Communications may be addressed to the Editor of Language Learning.

\section{INTRODUCTORY GENERAL WORKS}

Noam Chomsky, "A Transformational Approach to Syntax," Third Texas Conference on Problems of Linguistic Analysis in English (A. A. Hill, ed.) pp. 124-158. Austin: University of Texas, 1962. - A clear statement of what a generative grammar is, followed by a partial grammar of English in the form of phrasestructure rules and transformations. Some treatment of verbcomplement constructions. A brief consideration of phonological rules. (The discussion published with the report, pages $158-186$, is also valuable.)

R. B. Lees, "Some Neglected Aspects of Parsing," Language Learning 11.171-181 (1961). -Discusses some formal principles 
underlying certain traditional intuitive notions; e.g., deletion, imperative, bracketing.

H. A. Gleason, Jr., An Introduction to Descriptive Linguistics, Revised Edition (New York: Holt, 1961) Chapters 12 and 13. -A clear, brief account of the main ideas of generative grammar, compared with other kinds of grammar. Some sample transformations.

Paul Roberts, English Sentences. New York: Harcourt Brace, 1962. - A textbook applying the ideas of generative grammar to the teaching of English in the schools. Exercises in the use of transformations. (The Teacher's Manual gives additional technical background.)

Jean Malmstrom, "The Workshop on Generative Grammar," CCC (Journal of the Conference on College Composition and Communication) October 1962, pages 26-31. -Brief reports on papers by Chomsky, Lees, and DeCamp read at the 1962 meeting. (Reprints can be ordered from the National Council of Teachers of English, Champaign, Illinois.)

\section{MORE DIFFICULT GENERAL WORKS}

Z. S. Harris, "Co-occurrence and Transformation in Linguistic Structure," Language 33.283-340 (1957). - Proposes a method for studying systematic relationships between grammatical forms, including relationships between whole sentences.

Noam Chomsky, Syntactic Structures. The Hague: Mouton, 1957. Pp. 116. -The first general work outlining Chomsky's theory of generative grammar. Later publications have revised some of the rules for generating English sentences and have extended them to cover more of the restrictions, but the basic idea remains the same. (The second printing, 1962, contains additional bibliography.)

Noam Chomsky, Review of B. F. Skinner, Verbal Behavior, Language 35.26-58 (1959). - The last three pages deal with the importance of a theory of grammar as a prerequisite for investigation of the language-learning process.

Noam Chomsky, Review of Greenberg, Essays in Linguistics, Word 15.202-218 (1959). -Criticizes some of the procedures suggested by Greenberg for arriving at the basic elements 
of a language, particularly the words and morphemes.

R. B. Lees, Review of Chomsky, Syntactic Structures, Language 33.375-408 (1957). -A useful summary, with additional explanation, of some of the main points in the book.

R. B. Lees, The Grammar of English Nominalizations. Bloomington: Indiana University Research Center, 1960. Pp. xxviii + 206. - A summary of the theory, followed by rules for changing sentences into nominal expressions. Includes the most complete piece of English generative grammar so far. (See the reviews by Schachter in IJAL 28.134-146 and by Hill in Language $38.434-444$.)

Noam Chomsky, "On the Notion 'Rule of Grammar" " in $\mathrm{R}$. Jakobson (ed.) Structure of Language and its Mathematical Aspects (Proceedings of Symposia in Applied Mathematics, Vol. XII) Providence: American Mathematical Society, 1961. Pp. 6-24. -The requirements of a good grammar and how they might be met. Reasons for using transformations instead of generating all sentences by merely putting pieces together. Elementary and complex transformations. Constituent structure of transformed sentences.

Noam Chomsky, "Explanatory Models in Linguistics," in Ernest Nagel et al. (eds.) Logic, Methodology and Philosophy of Science (Proceedings of the 1960 International Congress) pp. 528-550. Stanford U. Press, 1962. -What a grammar must be like in order to explain how one learns a language. Includes a summary of what the phonological rules might be like for English.

\section{PARTICULAR PROBLEMS IN GRAMMAR}

Robert P. Stockwell, "The Place of Intonation in a Generative Grammar of English," Language 36.360-367 (1960). -The only readily available account to date of how intonation might fit into the rules for sentence formation.

R. B. Lees, "A Multiply Ambiguous Adjectival Construction in English," Language 36.207-221 (1960). --Part I recounts the shortcomings of some rival theories of grammar. Part II shows how transformations may shed light on the structural ambiguity in phrases like "ready to eat." 
R. B. Lees, "The Constituent Structure of Noun Phrases," American Speech 36.159-168 (1961). - "Definite" and "indefinite" as major categories of noun phrases. Explanation of the definite article "the" by deletion of a limiting phrase or clause. Three-way branching in the make-up of noun phrases.

R. B. Lees, "Grammatical Analysis of the English Comparative Construction," Word 17.171-185 (1961). -Restrictions on the content of comparative expressions accounted for by the use of complex transformations, paralleling the expansion of other major form classes (as nominalizations expand nominals).

Carlota S. Smith, "A Class of Complex Modifiers in English," Language 37.342-365 (1961). -Incorporates comparative constructions into the rules for formation of adjectival expressions.

Lila R. Gleitman, "Pronominals and Stress in English Conjunctions," Language Learning 11.157-169 (1961). -The reducedstress pronominal "one 1 " and the stressed indefinite article "one 2 " and their behavior in various transformations such as ellipsis and conjunction.

R. B. Lees and E. S. Klima, "Rules for English Pronominalization," Language 39.17-28 (1963). - The place in the grammar of rules for the reflexive "-self" and the reciprocal "each other."

Charles J. Fillmore, Indirect Object Constructions in English and the Ordering of Transformations. Columbus: Ohio State Research Foundation, 1962. -Verbs having a complement with deletable "to" or "for." Suggested revisions of the interrogative transforms.

\section{PHONOLOGY AND MORPHOPHONEMICS}

Noam Chomsky, Morris Halle, and Fred Lukoff, "On Accent and Juncture in English," For Roman Jakobson (The Hague, 1956) pp. 65-80. -Suggests how most of the contrasts in stress and juncture might be predicted by general rules, given the grammatical and lexical content. (Developed further in the "Explanatory Models" article cited at the end of section 2 above.)

Noam Chomsky, Review of Hockett, Manual of Phonology, IJAL 23.223-234 (1957). - Rejects transitional probability as a basis 
for syntax. Applauds Hockett's view of morphophonemics and his theory of phonological constituents. Some remarks on phonetic realism, analysis of data, theory-formation, and validation.

Noam Chomsky, Review of Jakobson and Halle, Fundamentals of Language, IJAL 23.234-241 (1957). -Briefly restates the distinctive-feature theory of phonology. Attacks complementary distribution and binary opposition if based on strict phonetic realism. Discusses criteria for evaluating a phonemic analysis.

Morris Halle, The Sound Pattern of Russian (The Hague: Mouton, 1959) pages 11-44. - Pending the appearance of Chomsky and Halle's book on English phonology, this is the best account of how they propose to describe the pronunciation of a language and fit it into the overall grammatical scheme.

Morris Halle, "Phonology in Generative Grammar," Word 18.54-72 (1962). --Argues for encoding grammatical forms into sounds by way of the distinctive features of each segment, on the grounds that this will simplify the morphophonemics, the phonotactics, and the explanation of sound changes.

\section{GRAMMAR AND SEMANTICS}

Hilary Putnam, "Some Issues in the Theory of Grammar" in R. Jakobson (ed.) Structure of Language and its Mathematical Aspects (Proceedings of Symposia in Applied Mathematics, Vol. XII) Providence: American Mathematical Society, 1961. Pp. 25-42. -Discusses Paul Ziff's notion of deviations from grammaticality and the implications thereof for generative grammar. Points out the difficulty of delimiting linguistic theory so that it applies to all and only those sets of sentences that can be generated by recursive rules. (Compare Katz's review of Ziff in Language 38.52-69.)

Noam Chomsky, "Some Methodological Remarks on Generative Grammar," Word 17.219-239 (1961). -Answers some criticisms based on degrees of grammaticality. Suggests criteria for identifying deviant sentences and the level of deviance involved, whether grammatical or semantic. (The first few pages give a summary of the general theory.)

R. B. Lees, "The Grammatical Basis of Some Semantic Notions," Report of the 11th Annual Round Table on Linguistics (ed. 
Choseed) pages 5-20. Washington: Georgetown U., 1962. -Modification as a grammatical rather than a semantic notion. Some important revisions and additions to the rules in his Grammar of English Nominalizations. 